\title{
Comparison of Antiaging and Antioxidant Activities of Protocatechuic and Ferulic Acids
}

\author{
Ermi Girsang ${ }^{1}$, I Nyoman Ehrich Lister ${ }^{1}$, Chrismis Novalinda Ginting ${ }^{1}$, Maulidwina Bethasari², \\ Annisa Amalia ${ }^{2}$, Wahyu Widowati ${ }^{3}$ \\ ${ }^{1}$ Faculty of Medicine, Universitas Prima Indonesia, Medan, Indonesia \\ ${ }^{2}$ Biomolecular and Biomedical Research Center, Aretha Medika Utama, Bandung, Indonesia \\ ${ }^{3}$ Faculty of Medicine, Maranatha Christian University, Bandung, Indonesia
}

Background: Skin-aging is a progressive changes in the skin combine with cumulative extrinsic factors which are mostly caused by free radicals caused by exposure to lots of free radicals molecules from pollutant, wrongly food intake, or too much sun bathing. These free radicals can be tackled by a treatment using antioxidants. Prevention of aging can be done by escalating antioxidant intake. Protocatechuic acid (PCA) and Ferulic acid (FA) have been known for their scavenging properties on free radicals and antiaging activity. Antioxidant and antiaging activity of both compounds have not been compared comprehensively before. Hence, current study was conducted to compare the potential of PCA and FA for their antioxidant and antiaging activities using various methods.

Materials and Methods: Antioxidant analysis of PCA and FA was conducted using $\mathrm{H}_{2} \mathrm{O}_{2}$ scavenging assay, 2,2'-azinobis-3ethylbenzo-thiazoline-6-sulfonic acid (ABTS), 2,2-diphenyl-1-picrylhydrazil (DPPH), and ferric reducing antioxidant power (FRAP). Meanwhile, antiaging activities of PCA and FA were examined using inhibitory activities of tyrosinase, collagenase, elastase, hyaluronidase and tyrosinase.

Results: $I_{50}$ of scavenging activity of ABTS were $125.18 \mu \mathrm{g} / \mathrm{mL}$ (PCA) and $35.55 \mu \mathrm{g} / \mathrm{mL}$ (FA), inhibition activity of collagenase were $126.16 \mu \mathrm{g} / \mathrm{mL}$ (PCA) and $52.85 \mu \mathrm{g} / \mathrm{mL}$ (FA) and inhibition activity of tyrosinase were $246.42 \mu \mathrm{g} / \mathrm{mL}$ (PCA), $253.58 \mu \mathrm{g} /$ $\mathrm{mL}$ (FA).

Conclusion: In conclusion, FA has better ABTS scavenging and collagenase inhibition activities compared to PCA. Meanwhile, PCA has better activity of tyrosinase inhibition than FA.

Keywords: antioxidant, antiaging, ferulic acid, protocatechuic acid

\section{Introduction}

The most common and ongoing dermatological problem is aging of the skin, especially in women. ${ }^{1,2}$ Unwanted changes that occur on the skin will be very visible because the skin is the outermost layer. This change occurs due to aging which has a wide effect on all body systems, the integumentary system is one of them. ${ }^{3}$ There are two types of skin aging, 
natural or intrinsic aging and photo or extrinsic aging. The differences between them are that natural or intrinsic aging is inevitable, cannot be prevented and originates in the body while extrinsic or photoaging can be avoided and prevented due to outside the body origins such as excessive exposure to ultraviolet (UV) A and UV B solar radiation. Rough, dull, saggy skin, wrinkles are results of aging. ${ }^{2,4}$

External aging caused by UV can induce functional reduction, protein biosynthesis decrement, and internal aging. ${ }^{5}$ Oxidative stress is a leading role in the aging process that causes the complex interactions in the integument system so that the resulting formation of wrinkles, pigmentation and asteatosis. ${ }^{2,6,7}$ Therefore, compounds that act as fair antioxidant and anti-inflammatory activities are expected to inhibit formation of pigmentation and wrinkle by affecting biosynthesis of melanin and collagen. ${ }^{5}$ Basically, our body produces reactive oxygen species (ROS) during metabolism. Induction of extrinsic factors such as UV will cause an increase of ROS in the body. This increment will weaken the function of several components in the skin, including fibroblast, collagen, elastin and hyaluronic acid. The effect is wrinkles, that can be caused by the destruction of collagen and elastin structure with the increasing expression of matrix metalloproteinases (MMPs) ${ }^{8}$ Other than ROS, enzymes such as hyaluronidase, elastase, tyrosinase, and collagenase can affect skin proteins that maintain the structure and elasticity of the skin. ${ }^{9}$ Hence, inhibition of ROS and those enzymes activities are needed in order to prevent aging.

Antiaging and cosmetic procedures (gels, oils, creams, powders, lotions) are widely produced and are thought to reduce or delay the aging process by inhibiting the activity of ROS and enzymes mentioned earlier. ${ }^{1,4}$ Polyphenols are antioxidants that can be found in food and plants, often used as ingredients in the manufacture of antiaging products. ${ }^{10-12}$ Examples of the most common polyphenols are protocatechuic acid (PCA) and ferulic acid (FA).

Many studies have mentioned that FA has various activities such as free radical cleansing and cytotoxicity activities, prevention of photo-oxidative skin damage, antioxidant protection. Especially as an antioxidant that can potentially prevent aging. ${ }^{13-15}$ PCA and FA can be found in fruits such as snake fruit (Salacca zalacca) and nuts, such as almonds (Prunus amygdalus). ${ }^{17,18}$ Products made from olive oil or white wine contains PCA and this polyphenol has been reported to have anti-bacterial, anti-cancer, antioxidant, antiatherosclerotic, anti-ulcer, anti-diabetic, hepatoprotective, antiaging, antiviral, anti-inflammatory, analgesic, cardiac, neurological and nephron-protection activities. ${ }^{19}$

Both of phenolic compounds are abundant in nature and have pharmacological effect. Hence, this study is aimed to compare the antioxidant and antiaging activity of both compounds comprehensively through radical scavenging assay for antioxidant and aging related enzymes inhibition activity.

\section{Materials and methods}

\section{Hydrogen Peroxide ( $\left.\mathrm{H}_{2} \mathrm{O}_{2}\right)$ Scavenging Activity Assay}

Protocatechuic acid, 4-Carboxy-1,2-dihydroxybenzene (Catalogue \#BP1155, Chengdu Biopurify Phytochemicals Ltd, Chengdu, China) and Ferulic acid, 4-hydroxy-3methoxycinnamic acid (Catalogue \#BP0586, Chengdu Biopurify Phytochemicals Ltd), each were dissolved using 10\% DMSO (Catalogue \#1.02952.1000, Supelco, Missouri, Amerika) in various concentrations. $\mathrm{H}_{2} \mathrm{O}_{2}$ scavenging activity was measured by the method according to previous study. The reaction begins by adding each reagent and sample to the 96 well plate, $12 \mu \mathrm{L}$ of $1 \mathrm{mM}$ ferrous ammonium sulphate (Catalogue \#215406, Sigma-Aldrich, Missouri, USA), $60 \mu \mathrm{L}$ of various concentration sample (PCA, FA), and $3 \mu \mathrm{L}$ of $5 \mathrm{mM} \mathrm{H}_{2} \mathrm{O}_{2}$ (Catalogue \#1.08597.1000, Merck) was incubated at dark room temperature for $5 \mathrm{~min}$. Briefly, it was added 1,10-phenanthroline (Catalogue \#131377, Merck) (1 mM, 75 $\mu \mathrm{L})$ the total volume in each plate was $150 \mu \mathrm{L}$, and then incubated for $10 \mathrm{~min}$ at room temperature. Absorbance was measured at wavelength of $510 \mathrm{~nm}$ using spectrophotometer (Catalogue \#N10588 Multiskan-Go, Thermo Fisher Scientific Inc., Vantaa, Finlandia). The result was depicted as scavenging percentage that was calculated using the following formula ${ }^{20}$ :

$$
\mathrm{H}_{2} \mathrm{O}_{2} \% \text { scavenging }=(\mathrm{S} / \mathrm{C}) \times 100
$$

$\mathrm{C}=$ absorbance of activity without sample

$\mathrm{S}=$ absorbance of activity with the addition of samples tested

\section{The 2,2'-azinobis-3-ethylbenzo-thiazoline-6-sulfonic acid} (ABTS) Radical Scavenging Assay

The ABTS radical scavenging assay was done using a method previously described according to previous study. ${ }^{21}$ The working solution was prepared by mixing $14 \mathrm{mM}$ ABTS (Catalogue \#A1888, Merck) and $4.9 \mathrm{mM} \mathrm{K}_{2} \mathrm{~S}_{2} \mathrm{O}_{8}$ (Catalogue \#EM105091, Merck) in equal quantities. Both 
reagents were left to react in the dark overnight at room temperature. Dilution with water was done untill absorbance of $0.70 \pm 0.03$ at $734 \mathrm{~nm}$ obtained. The ABTS solution (200 $\mu \mathrm{L}$ ) mixed with $20 \mu \mathrm{L}$ various concentration of samples, and the absorbance was measured at $734 \mathrm{~nm}$ after $6 \mathrm{~min}$ of incubation at room temperature. ABTS reducing activity was measured using the formula:

$\%$ ABTS Reducing Activity $=($ Ac - As $) /$ Ac x 100

Ac $=$ negative control absorbance (without sample)

As $=$ sample absorbance

\section{The 2,2-Diphenyl-1-picrylhydrazil (DPPH) Radical} Scavenging Assay

The DPPH radical scavenging assay was done according to previous study. ${ }^{22}$ About $200 \mu \mathrm{L}$ of $0.077 \mathrm{mM} \mathrm{DPPH}$ (Catalogue \#D9132, Merck) were added to 96-well plate (Catalogue \#30096, SPL Life Sciences, Pocheon, Korea) containing a range of samples concentrations $(50 \mu \mathrm{L}$ each well). At blank well, $250 \mu \mathrm{L}$ sample solvent (dimethyl sulfoxide (DMSO)) was added and for control well, $250 \mu \mathrm{L}$ of $0.077 \mathrm{mM}$ DPPH was added. The mixture was incubated in a dark chamber for $30 \mathrm{~min}$ at room temperature. Microplate spectrophotometer was used to measure the absorbance $(\lambda=$ $517 \mathrm{~nm})$. Percentage of scavenging activity was calculated using formula below. The DPPH scavenging activity was measured using the formula:

$\%$ DPPH Scavenging Activity $=($ Ac - As $) /$ Ac x 100

Ac $=$ negative control absorbance (without sample)

As $=$ sample absorbance

\section{The Ferric Reducing Antioxidant Power (FRAP) Assay}

Briefly $10 \mathrm{~mL}$ of $300 \mathrm{mM}$ acetate buffer (pH 3.6 adjusted with addition of acetic acid) $1 \mathrm{~mL}$ of $10 \mathrm{mM} \mathrm{2,4,6-Tris(2-}$ pyridryl)-s-triazine (TPTZ) (Catalogue \#T1253, Supelco, Missouri, USA), and $1 \mathrm{~mL}$ of $20 \mathrm{mM}$ ferric chloride hexahydrate (Catalogue \#1.03943.0250, Supelco) were mixed as FRAP reagent. $7.5 \mu \mathrm{L}$ of sample in various concentration and standard $\mathrm{FeSO}_{4}$ was inserted into samples well and blank well, consecutively. As much as $142.5 \mu \mathrm{L}$ FRAP was added to the well plate (Catalogue \#30096, SPL Life Sciences) containing the sample (well sample). In well blank, $142.5 \mu \mathrm{L}$ sample solvent (DMSO) was added instead. The plate was incubated for $6 \mathrm{~min}$ at $37^{\circ} \mathrm{C}$. The absorbance was measured using a microplate reader at $\lambda=745 \mathrm{~nm}$. FRAP activity was measured based on the linear equation of the standard $\mathrm{FeSO}_{4}$ curve. Ferrous reducing activity of sample was calculated based on $\mathrm{FeSO}_{4}$ standard curve. 23,24

\section{The Tyrosinase Inhibition Assay}

Inhibition of tyrosinase was evaluated based on dihydroxyphénylalanine (DOPA) chrome formation measured as previously described. ${ }^{25}$ Samples were dissolved in solvent resulted in varied concentrations. Samples were prepared in a 96-well plate (Catalogue \#30096, SPL Life Sciences), and the components were added as follows: $20 \mathrm{mM}$ phosphate buffer (pH 6.8), $20 \mu \mathrm{L}$ of sample and $20 \mu \mathrm{L}$ tyrosinase from mushroom (125 U/mL, Catalogue \#T3824, Sigma-Aldrich). Volume of phosphate buffer added into control, sample, and blank well were 160, 140, and $160 \mu \mathrm{L}$. Furthermore, a mixture of $20 \mu \mathrm{L}$ of $1.5 \mathrm{mM}$ L-DOPA substrate (Catalogue \#D9628, Sigma-Aldrich) was added. After incubation at $25^{\circ} \mathrm{C}$ for $10 \mathrm{~min}$, the tyrosinase inhibition activity was determined by measuring the absorbance at at $470 \mathrm{~nm}$, with following formula:

$\%$ Tyrosinase Inhibition Activity $=($ Ac - As $) /$ Ac x 100

Ac $=$ negative control absorbance (without sample)

As $=$ sample absorbance

\section{The Collagenase Inhibition Assay}

The measurement of N-[3-(2-Furyl)acryloyl]-Leu-Gly-ProAla (FALGPA) hydrolysis was carried out as a collagenase inhibition test using the method described previously. ${ }^{22}$ The test was carried out in $50 \mathrm{mM}$ tricine buffer, containing 10 $\mathrm{mM} \mathrm{CaCl}_{2}$ (pH 7.5) and $400 \mathrm{mM} \mathrm{NaCl} .10 \mu \mathrm{L}$ collagenase from Clostridium histolyticum (Catalogue \#C8051, SigmaAldrich) $(0.01 \mathrm{U} / \mathrm{mL}$ in cold aquadest) was added to each well, followed by addition of $90,60,80 \mu \mathrm{L}$ of Trycine buffer to control, sample, and blank well, respectively. After that, $30 \mu \mathrm{L}$ sample with various concentration were added and followed by incubation for $15 \mathrm{~min}$ at $37^{\circ} \mathrm{C}$. Last, FALGPA (Catalogue \#F5135, Sigma-Aldrich) that were dissolved in the tricine buffer for use at initial concentrations of $1 \mathrm{mM}$ was added to each well. Collagenase activity was measured at $335 \mathrm{~nm}$, with following formula:

$\%$ Collagenase Inhibition Activity $=($ Ac - As $) /$ Ac x 100

Ac $=$ negative control absorbance (without sample)

As $=$ sample absorbance 


\section{The Elastase Inhibition Assay}

Elastase inhibition was assayed using the method according to previous study. ${ }^{23}$ The color intensity of the solution was measured following elastase-mediated N-Succinyl-Ala-AlaAla-p-Nitroanilide (SANA) (Catalogue \#S4760, SigmaAldrich) cleavage to be the basis for determining inhibition. First of all, $1 \mathrm{mM}$ SANA was prepared in $0.1 \mathrm{M}$ Tris- $\mathrm{HCl}$ buffer (pH 8.0). Sample (10 $\mu \mathrm{L})$ in various concentration. Five $\mu \mathrm{L}$ of elastase was added into control and sample well. About $135,125,130 \mu \mathrm{L}$ of Tris-HCl buffer $0.1 \mathrm{M}$ (pH 8.0) $(200 \mu \mathrm{L})$ was added to control, sample, and blank well, respectively. The solutions were vortexed and preincubated for $15 \mathrm{~min}$ at $15^{\circ} \mathrm{C}$, and then $10 \mu \mathrm{L}$ of SANA substrate $(2$ $\mathrm{mg} / \mathrm{mL}$ in Tris buffer) solution was added then vortexed and placed in a $25^{\circ} \mathrm{C}$ water bath for $15 \mathrm{~min}$. Absorbance was measured at $410 \mathrm{~nm}$. The percentage of elastase inhibition activity was calculated with following formula:

$\%$ Elastase Inhibition Activity $=(\mathrm{Ac}-\mathrm{As}) / \mathrm{Ac} x 100$

Ac $=$ negative control absorbance (without sample)

As $=$ sample absorbance

\section{The Hyaluronidase Inhibition Assay}

Inhibition of hyaluronidase was determined according to previous study. ${ }^{23}$ A mixture of enzyme diluent consisted of a $5 \mu \mathrm{L}$ of hyaluronidase derived from bovine solution containing $1.50 \mathrm{U}$ of enzyme in $100 \mu \mathrm{L}$ of solution comprising $20 \mathrm{mM}$ ( $\mathrm{pH} \mathrm{7.0)}$ sodium phosphate buffer, $77 \mathrm{mM}$ sodium chloride, and $0.01 \%$ bovine serum albumin (BSA) was incubated for $10 \mathrm{~min}$ at $37^{\circ} \mathrm{C}$. In addition, a control containing $3 \mu \mathrm{L}$ enzymes and $37 \mu \mathrm{L}$ phosphate buffers and a blank containing $15 \mu \mathrm{L}$ phosphate buffers and $25 \mu \mathrm{L}$ samples were incubated at $37^{\circ} \mathrm{C}$ for $10 \mathrm{~min}$. Rooster comb derived hyaluronic acid sodium $(10 \mu \mathrm{L}$ in $0.03 \%$ in $300 \mathrm{mM}$ sodium phosphate, $\mathrm{pH}$ 5.35) was added to the mixture, followed by incubation for $45 \mathrm{~min}$ at $37^{\circ} \mathrm{C}$. Acid albumin solution $(1 \mathrm{~mL})$ was added to precipitate undigested hyaluronic acid. The solution composed of $79 \mathrm{mM}$ acetic acid ( $\mathrm{pH} 3.75$ ) and $0.1 \% \mathrm{BSA}$ in $24 \mathrm{mM}$ sodium acetate. The solution was allowed to stand for $10 \mathrm{~min}$ at room temperature, absorbance was measured using a spectrophotometer (600 $\mathrm{nm}$ ). The percentage of hyaluronidase inhibition activity was calculated with following formula:

$\%$ Hyaluronidase Inhibition Activity $=($ Ac - As $) / A c x 100$

$\mathrm{C}=$ absorbance of enzyme activity without sample

$\mathrm{S}=$ absorbance of enzyme activity with the addition of samples tested

\section{Statistical Analysis}

All the experiment was done in triplicate. Statistical analysis was conduct using SPSS software (Version 20.0, IBM Corporation, New York, America). Data were presented as mean \pm standard deviation. The Significant differences within the groups were determined using the Analysis of variance (One Way ANOVA) followed by Tukey's HSD Post-hoc Test. Significance of difference between PCA and FA activities were analyzed using the Independent Samples Mann-Whitney U-Test

\section{Results}

Antioxidant and antiaging activity of PCA and FA can be seen in Figure 1 and Figure 2. Post hoc test on results on each assay indicate the activities of both compounds on each assay are in concentration dependent manner. The concentration of both compounds are directly proportional to each activity. $\mathrm{IC}_{50}$ of Antioxidant and Antiaging activity of PCA and FA can be seen on Table 1 and Table 2. PCA activities on inhibition of tyrosinase, elastase, and hyaluronidase are higher compared to FA. PCA also have higher $\mathrm{H}_{2} \mathrm{O}_{2}$ and DPPH scavanging activity compared to FA. Meanwhile, on other assay, FA has higher activity. Statistic results using Independent Samples Mann-Whitney

Table 1. The $\mathrm{IC}_{50}$ value of antioxidant activity of PCA and FA.

\begin{tabular}{|c|c|c|c|c|c|c|c|}
\hline \multirow{3}{*}{$\begin{array}{l}\text { Substances } \\
\text { Unit }\end{array}$} & \multicolumn{6}{|c|}{ Scavenging Assay of } & \multirow{3}{*}{$\begin{array}{c}\begin{array}{c}\text { Activity at The } \\
\text { Highest } \\
\text { Concentration }\end{array} \\
\text { FRAP }(\mu \mathrm{M} \mathrm{FeII} / \mu \mathrm{g})\end{array}$} \\
\hline & \multicolumn{2}{|c|}{$\mathrm{H}_{2} \mathbf{O}_{2}$} & \multicolumn{2}{|c|}{ ABTS } & \multicolumn{2}{|c|}{ DPPH } & \\
\hline & $\mu \mathrm{M}$ & $\mu \mathrm{g} / \mathrm{mL}$ & $\mu \mathrm{M}$ & $\mu \mathrm{g} / \mathrm{mL}$ & $\mu \mathrm{M}$ & $\mu \mathrm{g} / \mathrm{mL}$ & \\
\hline PCA & 274.14 & 42.25 & 812.22 & 125.18 & 92.2 & 14.21 & 480.08 \\
\hline FA & 377.85 & 73.37 & 183.08 & 35.55 & 130.34 & 25.31 & 526.50 \\
\hline
\end{tabular}



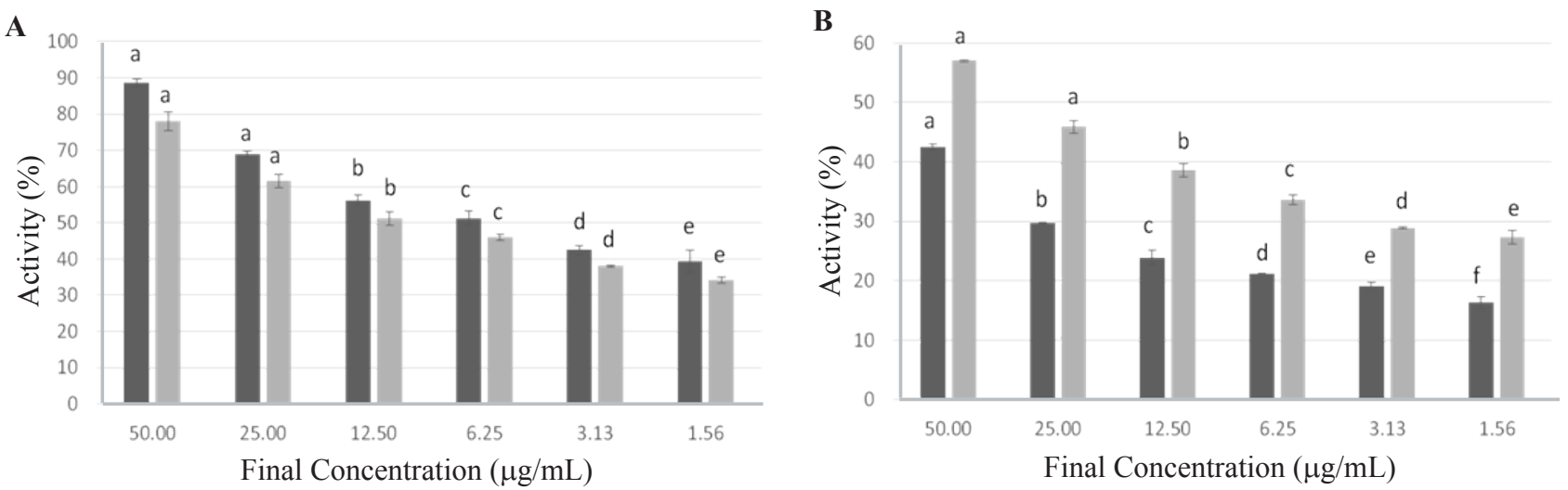

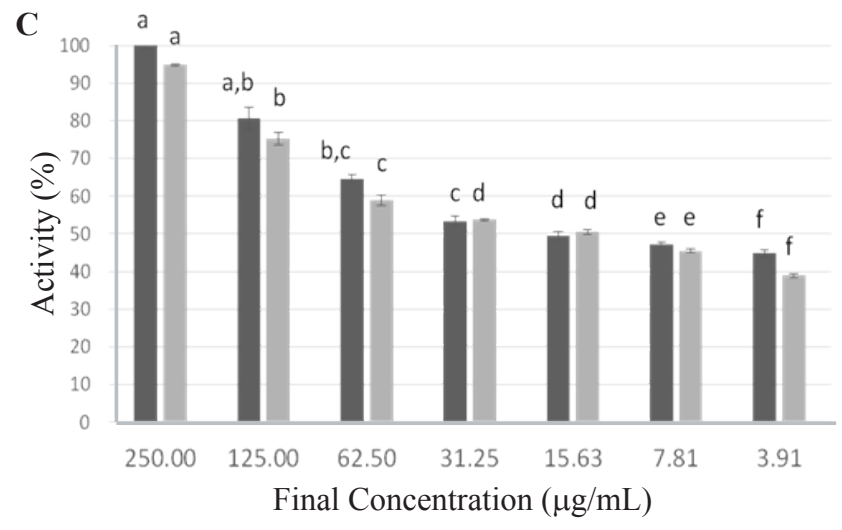

- Protocatechuic Acid

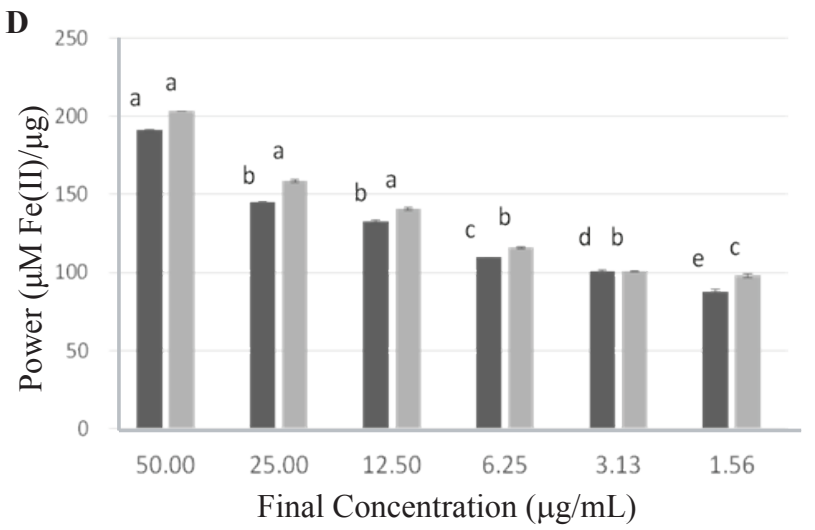

= Ferulic Acid

Figure 1. Antioxidant activity of PCA and FA. A: $\mathrm{H}_{2} \mathrm{O}_{2}$ scavenging activity, different letter (a,b,c,d,e) in the black histogram indicated significant differences among concentrations of PCA, and (a,b,c,d,e) in the gray histogram indicated significant differences among concentration of FA; B: ABTS scavenging activity, different letter (a,b,c,d,e,f) in the black histogram indicated significant differences among concentrations of PCA, and (a,b,c,d,e) in the gray histogram indicated significant differences among concentration of FA; C: DPPH scavenging activity, different letter (a,ab,b,bc,c,d,e,f) in the black histogram indicated significant differences among concentrations of PCA, and (a,b,c,d,e,f) in the gray histogram indicated significant differences among concentration of FA; D: FRAP assay, different letter (a,b,c,d,e) in the black histogram indicated significant differences among concentrations of PCA, and $(a, b, c)$ in the gray histogram indicated significant differences among concentration of FA. Data were presented as mean \pm standard deviation.

U-Test shows significant difference of ABTS scavenging, collagenase inhibition, and tyrosinase inhibition activity between PCA and FA $(p<0.05)$. Other assays resulted in insignificant difference between PCA and FA.

\section{Discussion}

The constituent components of the skin are the complex structures of non-cellular cellular and extra-cellular (ECM) matrix (glycoprotein, elastin, hyaluronic acid, collagen). The cellular process in the skin is influenced by ECM and also acts as a defense to prevent skin damage. All components play a functional role to keep the skin in the proper conditions. However, over time, the levels of each component decrease as a result of several biochemical processes that occur in the body that produce various clinical manifestations associated with aging. In this context, the use of an extract containing a wide range of topical materials has been proven effective as photoprotector against UV radiation and as an immune suppressant nuclear factor (NF)- $\kappa \beta$ pathway. In general, antioxidants act as metal chelators, inhibitors of lipid peroxidation and ROS scavengers and incorporated in cosmetic formulations for reducing the effects of aging. ${ }^{8}$ Thus, they can be effective 
A

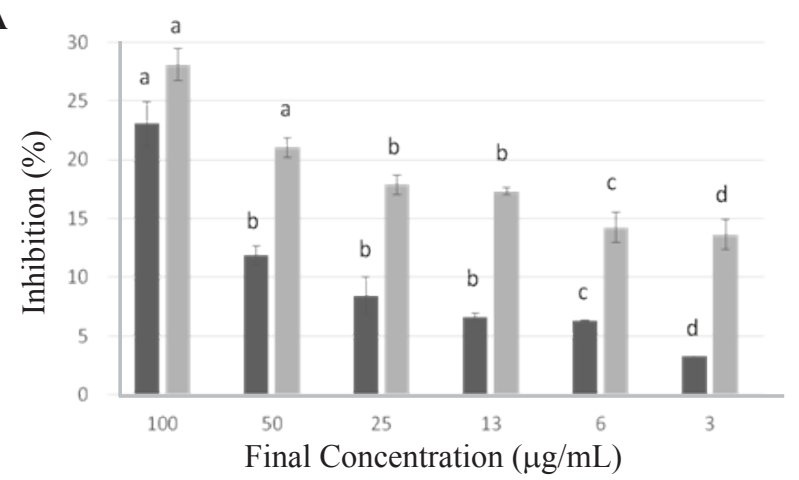

C

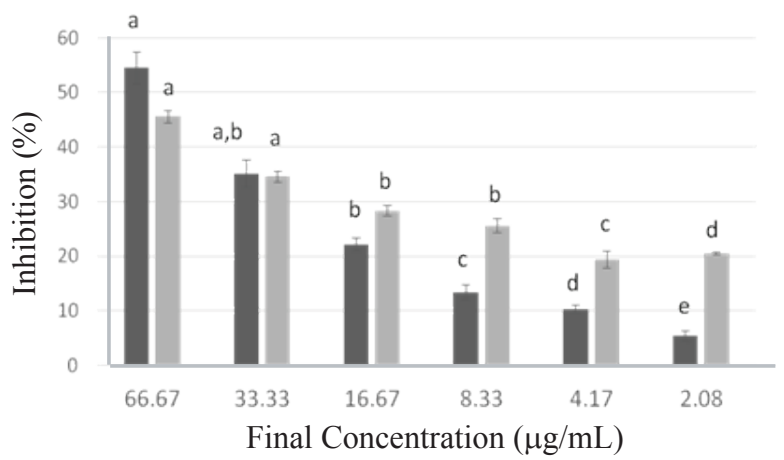

B
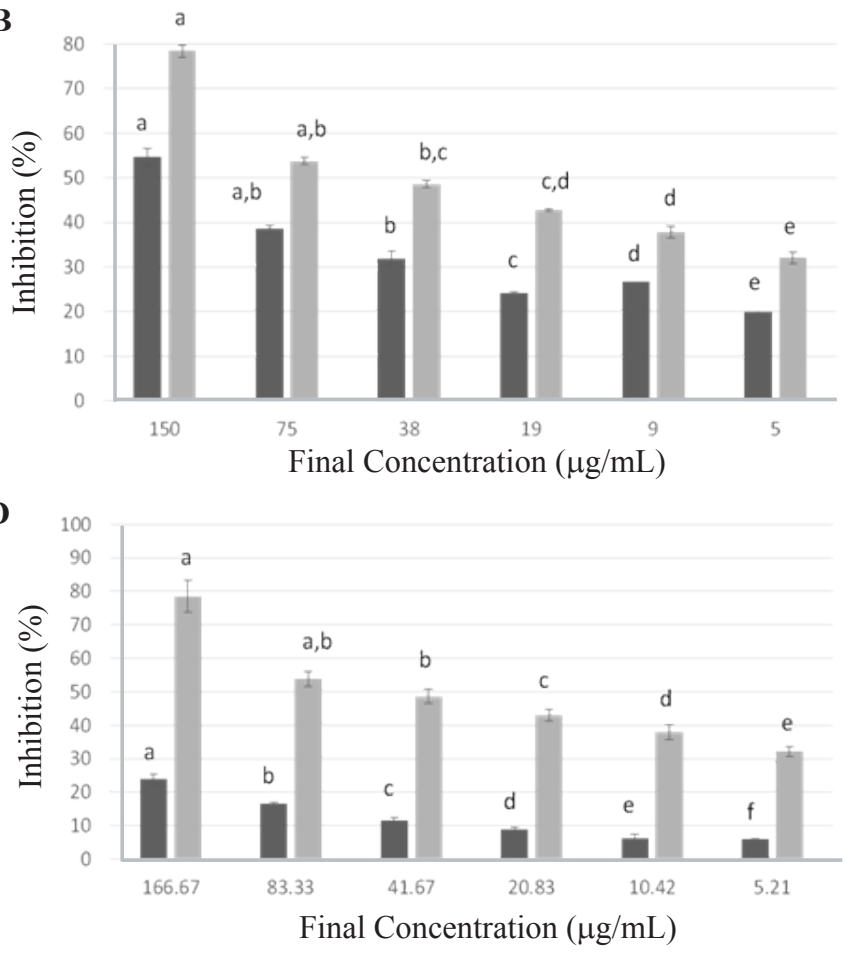

- Protocatechuic Acid = Ferulic Acid

Figure 2. Anti-aging activity of PCA and FA. A: tyrosinase inhibition activity, different letter (a,b,c,d) in the black histogram indicated significant differences among concentrations of PCA, and (a,b,c,d) in the gray histogram indicated significant differences among concentration of FA; B: collagenase inhibition activity, different letter $(\mathrm{a}, \mathrm{ab}, \mathrm{c}, \mathrm{d}, \mathrm{e})$ in the black histogram indicated significant differences among concentrations of PCA, and (a,ab,bc,cd,d,e) in the gray histogram indicated significant differences among concentration of FA; C: elastase inhibition activity, different letter (a,ab,b,c,d,e) in the black histogram indicated significant differences among concentrations of PCA, and $(a, b, c, d)$ in the gray histogram indicated significant differences among concentration of FA; D: hyaluronidase inhibition activity, different letter (a,b,c,d,e,f) in the black histogram indicated significant differences among concentrations of PCA, and (a,ab,b,c,d.e) in the gray histogram indicated significant differences among concentration of FA. Data were presented as mean \pm standard deviation.

as an anti-wrinkle and depigmentation, thereby preventing damage from UV radiation, whose effects lead to the generation of ROS, enhance the expression of MMP-1 and tyrosinase, the enzyme responsible for the breakdown of collagen and hyperpigmentation. ${ }^{7}$ Most of antioxidant found in plants are in a form of phenolic compounds which are a group of secondary metabolites from fungi and plants. They are secreted as UV protectant, protection against other plants, insects, viruses and bacteria, and also responsible for plant color, smell, and flavor. ${ }^{26}$

Table 2. The $\mathrm{IC}_{50}$ value of anti-aging activity of PCA and FA.

\begin{tabular}{lcccccccc}
\hline \multirow{2}{*}{ Substances } & \multicolumn{8}{c}{ Inhibition Activity of } \\
\cline { 2 - 10 } & \multicolumn{2}{c}{ Tyrosinase } & \multicolumn{2}{c}{ Collagenase } & \multicolumn{2}{c}{ Elastase } & \multicolumn{2}{c}{ Hyaluronidase } \\
\hline Unit & $\mu \mathrm{M}$ & $\mu \mathrm{g} / \mathrm{mL}$ & $\mu \mathrm{M}$ & $\mu \mathrm{g} / \mathrm{mL}$ & $\mu \mathrm{M}$ & $\mu \mathrm{g} / \mathrm{mL}$ & $\mu \mathrm{M}$ & $\mu \mathrm{g} / \mathrm{mL}$ \\
PCA & 1305.9 & 246.42 & 818.58 & 126.16 & 374.32 & 57.69 & 697.96 & 107.57 \\
FA & 1598.88 & 253.58 & 272.17 & 52.85 & 389.38 & 75.61 & 2039.96 & 396.12 \\
\hline
\end{tabular}


Evidence from this study demonstrates that PCA exerts potent antioxidant effects. In other in vitro studies, PCA was shown to increase $\mathrm{H}_{2} \mathrm{O}_{2}$ scavenging activity and decreasing lipid peroxidation. ${ }^{27}$ PCA can decrease $\mathrm{H}_{2} \mathrm{O}_{2}$ production In J77A.1 macrophage. ${ }^{28,29}$ This compound can also improve mitochondrial function, inhibit DNA fragmentation in $\mathrm{H}_{2} \mathrm{O}_{2}$ induced oxidative stress in human nerve cells, and inhibit intracellular ROS levels thereby reducing apoptosis induced reactive oxygen species (ROS) in BNLCL2 cells. ${ }^{30-32}$ PCA also decreases Advance Glycation End (AGEs) and ROS products in D-galactose in ROS rats and induced AGE formations. ${ }^{33}$ PCA also has functions to restore the endogenous antioxidant enzyme activity in streptozotocin induced diabetic rats so that ROS is not formed in the liver, kidneys and brain. ${ }^{34,35}$ All of these findings of PCA's potential antioxidant activity suggesting that this compound can be used as complementary antioxidant and antiaging.

The results of PCA isolated from Alpinia activity which significantly reduced Malondialdehyde (MDA) levels of old mice and increased spleen weight, and increased plasma and erythrocyte glutathione peroxidase activities (GSH-PX), and chloramphenicol acetyltransferase activity and. Endogenous antioxidant enzyme activity and normalization related changes showed that PCA Alpinia potential as an anti-aging potential and heart disease. It may be therapeutically useful to minimize damage disorders caused by oxidative damage. ${ }^{36}$ The result of antiaging activity of PCA in this study is in accordance with the result of previous reports. The reports stated that trough the suppression of melanogenic enzymes and microphthalmia-associated transcription factor (Mitf) in $\alpha$-melanocyte stimulating hormone-stimulated mouse melanoma cells PCA can decrease melanin content and cellular tyrosinase activity. ${ }^{37}$

A study in Spain also investigated the anti-collagenase activity of FA by measuring antioxidant defense parameters based on their photoprotective ability. ${ }^{38}$ In a review of FA concerning its cosmeceutical properties it was reported that the compound has the potential to inhibit melanin formation through competitive inhibition of tyrosinase. ${ }^{39}$

Antioxidant activities of phenolic compounds depend on the amount hydroxyl group contained in the structure because hydroxyl group of PCA and FA will react with radical species. This study results is not in accordance to this fact because PCA have more hydroxyl group compared to FA. A Comparison study of PCA to Trolox proven that PCA shows much more effective antioxidant activity in vitro via donating hydrogen atom $(\mathrm{H}+)$ or electron $(\mathrm{e})$. Both of compound also contain $-\mathrm{OH}$ and $-\mathrm{COOH}$ functional groups which enabling the compounds to chelate metal ion such as ferrous. In PCA, chelating activity arise from orthodihydroxyl groups. Previous study reported that the PCA $\mathrm{IC}_{50}$ for DPPH, ABTS, and FRAP are 1.88, 0.89, and 5.15 $\mu \mathrm{g} / \mathrm{mL}$ respectively. ${ }^{40,41}$ Compared to the result of this study, obtained $\mathrm{IC}_{50}$ is much higher. This result is probably due to the solvent used in dissolving PCA is different.

\section{Conclusion}

In conclusion, FA has better ABTS scavenging and collagenase inhibition activity compared to PCA. Meanwhile, PCA has better activity of tyrosinase inhibition than FA. Hence, both compounds have their own advantages. PCA is more accurate to be used as black spots remover due to its inhibition activity towards tyrosinase which is involved in melanin synthesis. Meanwhile FA is fitter to be used as anti-wrinkle due to its better inhibition activity on collagenase that break the peptide bonds in collagen.

\section{Acknowledgement}

This research was supported by Universitas Prima Indonesia, Medan-Indonesia and Aretha Medika Utama, Biomolecular and Biomedical Research Center, Bandung-Indonesia. We are thankful to Satrio Haryo Benowo Wibowo, Ubaydillah Zedd Munshy, Wahyu Setia Widodo, Rr. Anisa Siwianti Handayani, and Ika Adhani Sholihah, Dwi Surya Artie from Aretha Medika Utama Biomilecular and Biomedical Research Center Bandung.

\section{References}

1. Hori M, Yagi M, Nomoto K, Shimode A, Ogura M, Yonei Y. Inhibition of advanced glycation end product formation by herbal teas and its relation to anti-skin aging. Anti-aging Med. 2012; 9(6): 135-48.

2. Baumann L. Skin ageing and its treatment. J Pathol. 2007; 211(2): 241-51.

3. Carola R, Harley JP, Noback CR. Human Anatomy and Physiology. 1st ed. New York: McGraw-Hill Publishing Company; 1990.

4. Mukherjee PK, Maity N, Nema NK, Sarkar BK. Bioactive compounds from natural resources against skin aging. Phytomedicine. 2011; 19(1): 64-73.

5. Kwak CS, Yang J, Shin C, Chung JH. Topical or oral treatment of peach flower extract attenuates UV-induced epidermal thickening, matrix metalloproteinase-13 expression and pro-inflammatory cytokine production in hairless mice skin. Nutr Res Pract. 2018; 12(1): 29-40.

6. Kim J, Lee C, Kyung E, Lee S, Park N, Kim H, et al. Inhibition effect of gynura procumbens extract on uv-b-induced matrixmetalloproteinase expression in human dermal fibroblast. J 
Ethnopharmacol. 2011; 137(1): 427-33.

7. Chiang H, Chen H, Lin T, Shih I, Wen K. Michelia alba extract attenuates uvb-induced expression of matrix metalloproteinases via map kinase pathway in human dermal fibroblas. Food Chem Toxicol. 2012; 50(12): 4260-9.

8. Cho HPJ, Kim SHD, Cho HJIKY. Whitening and anti-wrinkle activities of ferulic acid isolated from tetragonia tetragonioides in B16F10 melanoma and CCD- 986sk fibroblast cells. J Nat Med. 2018; 72(1): 127-35.

9. Hong Y, Young E, Ouk D, Joo H. Physiological effects of formulation containing tannase-converted green tea extract on skin care: physical stability, collagenase, elastase, and tyrosinase activities. Integr Med Res. 2014; 3(1): 25-33.

10. Robbins RJ. Phenolic acids in foods: an overview of analytical methodology phenolic acids in foods. J Agric Food Chem. 2003; 51(10): 2866-87.

11. Liu RH. Nutrition and cancer potential synergy of phytochemicals in cancer prevention: mechanism of action 1. Int Res Conf Food. 2018; (February): 3479-85.

12. Hudson EA, Dinh PA, Kokubun T, Simmonds MSJ, Gescher A. Characterization of potentially chemopreventive phenols in extracts of brown rice that inhibit the growth of human breast and colon cancer cells 1. Cancer Epidemiol Biomarkers Prev. 2000; 9(November): 1163-70.

13. Nile SH, Ko EY, Kim DH, Keum Y. Screening of ferulic acid related compounds as inhibitors of xanthine oxidase and cyclooxygenase-2 with anti-inflammatory activity. Rev Bras Farmacogn. 2016; 26(1): 50-5.

14. Kanski J, Aksenova M, Stoyanova A, Butterfield DA. Ferulic acid antioxidant protection against hydroxyl and peroxyl radical oxidation in synaptosomal and neuronal cell culture systems in vitro: structure - activity studies. J Nutr Biochem. 2002; 13(5): 27381.

15. Saija A, Tomaino A, Proteggente A, Pas A De, Uccella N, Bonina F. Ferulic and caffeic acids as potential protective agents against photooxidative skin damage. J Sci Food Agric. 1999; 480: 476-80.

16. Kayano S, Kikuzaki H, Fukutsuka N, Mitani T, Nakatani N. Antioxidant activity of prune (Prunus domestica L.) constituents and a new synergist. J Agric Food Chem. 2002; 50(13): 370812.

17. Li P, Q Wang X, Z Wang H, Wu Y. High Performance liquid chromatographic determination of phenolic acids in fruits and vegetables. Biomed Environ Sci. 1993; 6(4): 389-98.

18. Fitri A. Identification of Phytochemical and Antioxidant Activity in Peel and Seed of Tropical Fruits from Indonesia. Bogor: Institut Pertanian Bogor; 2015.

19. Kakkar S, Bais S. A Review on protocatechuic acid and its pharmacological potential. Pharmacology. 2014; 2014: 952943. doi: 10.1155/2014/952943.

20. Utami S, Adityaningsari P, Sosiawan I, Endrini S, Romadhiyani Q. Antioxidants and anticholinesterase activities of the characterized ethanolic of ripe sesoot (Garcinia picrorrhiza Miq.) fruit extract (GpKar) and xanthone. Tradit Med J. 2017; 22(December): 160-5.

21. Widowati W, Janeva WB, Nadya S, Amalia A, Arumwardana S, Kusuma HSW, et al. Antioxidant and antiaging activities of Jasminum sambac extract, and its compounds. J Rep Pharmaceut Sci. 2018; 7(3): 270-85.

22. Widowati W, Fauziah N, Herdiman H, Afni M, Afifah E, Sari H. Antiepileptic and effects antioxidant and anti aging assays of oryza in acid sativa extracts, vanillin and coumaric acid. J Nat Remedies. 2016; 16(3): 1-12.
23. Widowati W, Rani AP, Hamzah RA, Arumwardana S, Afifah E. Antioxidant and antiaging assays of Hibiscus sabdariffa extract and its compounds. Nat Prod Sci. 2017; 23(3): 192-200.

24. Widowati W, Wargasetia TL, Afifah E, Mozef T, Kusuma HSW, Nufus $\mathrm{H}$, et al. Antioxidant and antidiabetic potential of Curcuma longa and its compounds. Asian J Agric Biol. 2018; 6(2): 14961.

25. Thi P, Tu B, Tawata S. Anti-oxidant, anti-aging, and anti-melanogenic properties of the essential oils from two varieties of Alpinia zerumbet. Molecules. 2015; 20: 16723-40.

26. Inês $M$, João $M$, Alves RC, Ferreira ICFR. Exploring plant tissue culture to improve the production of phenolic compounds: a review. Ind Crop Prod. 2015; 2015: 1-14. doi: 10.1016/j. indcrop.2015.12.016.

27. Sofic E, Lange KW, Jellinger K, Riederer P. Reduced and oxidized glutathione in the substantia nigra of patients with parkinson's disease. Neuroscience. 1992; 142(2): 128-30.

28. Tian L, Cai Q, Wei H. Alterations of antioxidant enzymes and oxidative damage to macromolecules in different organs of rats during. Free Radic Biol Med. 1998; 24(9): 1477-84.

29. Buettner GR. The pecking order of free radicals and antioxidants: lipid peroxidation, a-tocopherol, and ascorbate. Arch Biochem Biophys. 1993; 300(2): 535-43.

30. Newmark HL. Plant phenolic compounds as inhibitors of mutagenesis and carcinogenesis. Am Chem Soc. 1992; 507(4): 48-52.

31. Huang M, Ferraro T. Phenolic compounds in food and cancer prevention. Am Chem Soc. 2000; 507(2): 8-34.

32. Cini M, Fariello RG, Bianchetti A, Moretti AI. Studies on lipid peroxidation in the rat brain. Neurochem Res. 1994; 19(3): 283-4.

33. Tseng T, Kao T, Chu C, Chou F, Lin W, Wang C. Induction of apoptosis by hibiscus protocatechuic acid in human leukemia cells via reduction of retinoblastoma ( $\mathrm{rb}$ ) phosphorylation and bcl-2 expression. Biochem Pharmacol. 2000; 60(00): 307-15.

34. Ho Y, Magnenat J, Gargano M. The nature of antioxidant defense mechanisms: a lesson from transgenic studies. Environ Health Perspect. 1998; 106 (Suppl 5): 1219-28.

35. Zhang Z, Chang Q, Zhu M, Huang Y, Ho WKK, Chen Z. Characterization of antioxidants present in hawthorn fruits. J Nutr Biochem. 2001; 12(3): 144-52.

36. Zhang X, Shi GF, Liu X, An L, Guan S. Anti-ageing effects of protocatechuic acid from alpinia on spleen and liver antioxidative system of senescent mice. Cell Biochem Funct. 2011; 29(April): $342-7$.

37. Truong XT, Park S, Lee YG, Jeong HY, Moon JH, Jeon TI. Protocatechuic acid from pear inhibits melanogenesis in melanoma cells. Int J Mol Sci. 2017; 18(8): pii: E1809. doi: 10.3390/ ijms 18081809 .

38. Pluemsamran T, Onkoksoong T, Panich U. Caffeic acid and ferulic acid inhibit UVA-induced matrix metalloproteinase-1 through regulation of antioxidant defense system in keratinocyte $\mathrm{HaCaT}$ cells. Photochem Photobiol. 2012; 88(4): 961-8.

39. Kumar N, Pruthi V. Potential applications of ferulic acid from natural sources. Biotechnol Reports. 2014; 4: 86-93.

40. Aqil F, Munagala R, Jeyabalan J, Joshi T, Singh IP. The Indian blackberry (jamun), antioxidant capacity, and cancer protection. cancer: oxidative stress and dietary antioxidants. In: Cancer: Oxidative Stress and Dietary Antioxidants. Atlanta: Elsevier; 2014. p.101-13.

41. Li X, Wang X, Chen D, Chen S. Antioxidant activity and mechanism of protocatechuic acid in vitro xican. Funct Foods Heal Dis. 2011; 1(7): $232-44$ 